\title{
Attitudes of married individuals towards oral contraceptives: a qualitative study in Istanbul, Turkey
}

\author{
Melda Karavus, MD, Professor; Sanda Cali, MD, Professor; Sibel Kalaca, MD, MPH, Assistant Professor; \\ Dilsad Cebeci, MD, MPH, Assistant Professor, Department of Public Health, Faculty of Medicine, Marmara University, \\ Istanbul, Turkey
}

Correspondence: Prof. Melda Karavus, Department of Public Health, Faculty of Medicine, University of Marmara, Tibbiye Caddesi 49, Haydarpasa 34668, Istanbul, Turkey. Tel: +90 2164149457 . Fax: +90 2164144731.

E-mail: sandacali@superonline.com

(Accepted 9 February 2004)

Journal of Family Planning and Reproductive Health Care 2004; 30(2): 95-98

\begin{abstract}
Objective To determine positive and negative attitudes of married Turkish women and men regarding the use of oral contraceptives (OCs).

Methods Twenty focus group discussions were conducted during the period October 1998-March 1999 in Umraniye, which is one of the densely populated districts of Istanbul. Results Most of the negative attitudes relating to OCs stemmed from concerns over side effects, particularly in the male focus groups. Health care professionals' behaviour, lack of concern or bias, and their reluctance to prescribe also limited the uptake of OCs. The female groups had very positive attitudes towards OCs compared to those of the male groups. It was identified that although OCs are largely provided free of charge in Turkey, beliefs and attitudes towards them are the important factors which affect the uptake of the method.

Conclusion Special efforts may be needed to educate these groups and also to teach the health professionals about family planning counselling.

Key message points
- Turkish women do not commonly use oral contraceptives (OCs)
due to exaggerated perception of health risks.
- Participants stated that health professionals do not recommend
OCs as first choice of contraception.
Participants stated that the health care professionals' behaviour
is important in their lack of trust of medical methods.
\end{abstract}

\section{Introduction}

The purpose of this study was to obtain insights into why Turkish men and women may not find oral contraceptives (OCs) acceptable as a method of family planning. Although OCs are among the first choice of contraceptive methods in developed countries ${ }^{1-6}$ many misbeliefs and misperceptions still exist, and fear and ignorance about actual or perceived side effects still prevail. ${ }^{7,8}$ For these reasons OCs are not commonly used by women in developing countries who still depend upon traditional methods of contraception. ${ }^{9,10}$

A total of $37.7 \%$ of couples in Turkey use modern contraceptives and a further $25.5 \%$ use traditional methods. Withdrawal accounts for $95.8 \%$ of traditional methods. ${ }^{11}$ The modern methods available in Turkey are condoms, intrauterine devices (IUDs), injectables, implants and combined OCs. Male and female sterilisation is also available. All these methods are available free of charge in government-funded primary health care units and hospitals for married and unmarried clients. Pharmacies and private physicians also supply contraceptives but charge for their services. Although the pill is provided free of charge by state health facilities, the percentage of married women currently using this method is only $4.4 \% .{ }^{11}$ In Turkey the perceived side effects of contraception and basic health concerns are reported to be key influences in the initial decision to use modern contraceptive methods. ${ }^{12}$ This study was carried out to identify the positive and negative attitudes of the community about OCs in Umraniye, one of the densely populated districts of Istanbul, Turkey during the period October 1998-March 1999.

\section{Methods}

The research methodology used in this study is based on qualitative techniques. The neighbourhoods of Umraniye were divided into four categories with respect to their demographic, spatial, political and economic characteristics.

Twenty focus groups (10 female and 10 male) were held with participants selected according to region, gender, age, marital status and ability to speak and understand Turkish. Each focus group consisted of 7-11 participants and discussions lasted 45-60 minutes. All the participants selected were married. Female participants were in the fertile age group (15-49 years) and male participants were selected with respect to the age of their wives. The women were illiterates, literate or elementary school graduates. Most of the men were elementary school graduates.

In the preparation phase, a 5-day workshop managed by a social scientist was held on qualitative research methodology, conducting focus group discussions and analysis of focus group data. The questionnaire for the focus group discussions was prepared during this workshop. In the pilot phase two focus groups were organised to test the questionnaire in a neighbourhood not included in the study area but still in the region of Umraniye, and then the questionnaire was edited and revised. The questionnaire was made up of three sections (Methods, Decision Making and Services). In the Methods section the participants were asked about their knowledge of family planning methods and their positive and negative attitudes. In the Decision Making section, participants were asked how they decided which family planning method to use. In the Services section participants were asked about their experiences and perceptions of family planning services. To organise the groups, the research staff made visits to public places, mukhtars (elected heads of neighbourhoods), shops, nongovernmental local organisations and teahouses to find key contact persons. By following all possible contacts and social networks, people were invited to the groups individually. Only one person from a couple was invited to a focus group. Care was taken to ensure that the participants in any focus group did not know each other. This was to create a relaxed atmosphere in which to discuss private issues. Focus group meetings were held in local places, such as the office of the mukhtar, a local non-governmental 
organisation or the house of a participant. The focus groups were led by a moderator with two trained observers. Male researchers conducted the men's groups and female researchers conducted the women's groups. Informed consent was obtained from all the participants before the interviews. All the sessions were tape-recorded, transcribed and loaded into Ethnograph ${ }^{\circledR}$ software.

\section{Results}

A total of $60 \%$ of women and $54.4 \%$ of men were primary school graduates. The mean age of the participants was $32.0 \pm 7.2$ years. The majority of female participants were housewives. Approximately half of the men were traders and around one-fifth were labourers with $10 \%$ of men in no regular employment. An overview of the groups showed that most of the participants preferred traditional contraceptive methods especially withdrawal, due to negative attitudes about medical methods, particularly the pill. The male participants expressed negative attitudes about the pill including side effects, contraceptive effectiveness, religious factors, mistrust of civil authorities and economic barriers. The negative attitudes of the female participants included concerns about side effects and the rules for taking OCs as well as the attitude of the health service professionals towards OCs. Positive attitudes from both sexes included positive health effects of OCs and the fact that pill use does not affect or interrupt sexual intercourse. Contraceptive effectiveness as a benefit of OCs was stated only in women's groups (Table 1).

Negative attitudes towards pill use

Men's groups. The male participants stated that health hazards and side effects occurred during OC use, with two of the participants stating that long-term use of the pill would damage some body systems since all medicines have contraindications as well as health benefits.

Participants who mentioned side effects of the pill defined the most common ones as weight gain, increase in body hair, hormonal irregularities and the development of cancer. Weight gain was particularly attributed to the pill's hormonal basis. In addition, some of the participants mentioned beliefs about side effects of OCs leading to goitre and calcification. One participant stated that he had obtained information from a doctor friend that the pill was hazardous to health. Another participant stated that if the pill is not used under the guidance of a doctor this could lead to side effects and even cancer.

"The pill has many side effects. I mean it should have."

"It's hormonal ... if something consists of hormones it makes you fat."

"Other young couples have coitus everyday. Let's talk about these. If you use pills every day you have intercourse, your body would develop resistance to it. Woman's body would be in need of pills whether she would have coitus or not."

Table 1 Classification of negative and positive attitudes expressed by men's and women's groups

\begin{tabular}{lll}
\hline Attitudes & Men's groups & Women's groups \\
\hline Negative & Side effects & Side effects \\
& Religious aspects & Rules of use \\
& Contraceptive ineffectiveness & Approach of health \\
& Mistrust of civil authorities & service providers \\
& Economical barriers & \\
Positive & Positive health effects & Contraceptive effectiveness \\
& Not affecting sexual intercourse & Positive health effects \\
& & Not interrupting sexual \\
& & intercourse \\
\hline
\end{tabular}

"Now, we are talking about an ignorant man. He has vague knowledge and he says it's sold at the pharmacy. What is sold? Birth control pills! He goes but he knows nothing about side effects. There are various types of pills for each particular body condition. For example, an overweight woman of $100 \mathrm{~kg}$ goes and gets the pills for $60 \mathrm{~kg}$ woman. What happens? Side effects will appear. Sometimes it causes hormonal irregularities or even worse problems such as cancer."

Participants in the men's groups stated that the pill could cause spontaneous abortions in future pregnancies and that fertility would be delayed after using the pill.

"We have talked to another doctor friend about this. She said the same: that the length of use causes this result. You have to have a month interval in every 3 or 4 months."

"We know some women using pills for 2 years ... I mean I have relatives who are infertile now because of this. In other words woman is able to fertilise but it results in spontaneous abortion later..."

Some other negative views of the male participants were about problems in obtaining the pill, ineffectiveness of the pills, other side effects and religious factors.

"I don't accept that. Why? Religiously it's forbidden getting medicine, preventing pregnancy is a sin...."

"Abortion is another sin."

"Induced abortion is the sin."

Women's groups. The female participants stated side effects of the pill as the reason why the pill is less commonly chosen and then only used for short periods of time. The commonly mentioned side effects of the pill were weight gain, headache, nervousness, dizziness and menstrual irregularities. A few participants mentioned other complaints such as gastric tenderness, an increase in body hair and changes in mood. Menstrual irregularities were defined as shortened bleeding time, lengthened cycle or amenorrhoea.

"The pills were not good for me for the 9 months that I used them. I had a headache all that time and I couldn't get out of bed. When I tried to get up I felt dizzy. I quit it and decided on an IUD. In fact I would like to use pills if I did not have those side effects."

"I mean pills are not good for most of them."

"Pills have many side effects. Either they cause weight gain but sometimes loss of weight."

"In addition they say that they cause cancers."

"But pills are used."

"They've been used but nobody is using them any more. Because of those side effects they've stopped already."

One of the participants mentioned that women who are hypertensive and have kidney disease could not use the pill. Another stated that older women are not able to use OCs. The pill was thought to affect the liver and the kidneys leading to organ damage. Two of the participants said their husbands think that pills definitely have some side effects and this is why they are against their using them. Another participant stated that her older family members do not want her to use the pill.

Positive attitudes towards pill use

Men's groups. One participant opposed all the views that the pill hinders future pregnancies. He stated that they had had a baby when they wanted after using the pill as contraception for a long period of time. Another participant stressed that pill use may not lead to side effects if it was used under medical supervision. 
"The pills give no complaints if they are used under a doctor's control. But the doctor control is a must. Otherwise you go and get it from the pharmacy and you use it as you assume to do. In that case there would be complaints."

One of the participants stated the known contraceptive methods and pointed out that the pills were one of the three current methods in use.

"We accept three basic methods. First one is withdrawal, the second is intrauterine device (IUD) and the third is the pills, which are produced by the Ministry of Health. We depend on those three."

Another participant commented that he believed his wife had enough knowledge about family planning methods and that she had chosen pills as the most suitable method for herself and continued to use them.

Women's groups. Participants stated that unwanted side effects of pill use could be eliminated if the user instructions were well understood and followed. In addition, it was recognised that health checks are required before starting the pill. The female participants understood the pill's effect on menstrual cycle regulation. The pill users talked about the effectiveness of OCs and stated that they had not experienced an increase in body hair or nervousness.

"I use pills and I feel comfortable psychologically. I mean you are sure of its effectiveness and it also regulates my periods. I was already nervous before I used them and I don't believe it has got more severe now."

"It is effective. It prevents unwanted pregnancies."

A participant summarised other positive aspects of OCs as follows:

"You control the pills; everything is in your hand. I can carry it with me everywhere. The only regulation is not to forget to take it on time. I felt that it causes some depression in me but I am sure it will become less and go in time. The method is my own choice. Using this method is for my benefit. If I leave the responsibility to the other side any single hitch would bring me trouble...."

\section{Discussion}

In this study an overview of the groups showed that most of them preferred traditional contraceptive methods, particularly withdrawal, because of a variety of negative attitudes to medical methods particularly the pill. All of the people surveyed in the 1998 Population and Health Survey of Turkey ${ }^{11}$ were aware of the pill as a method of family planning. Some $34 \%$ of married women had used the pill at some time in their lives however only $4.4 \%$ were currently using the pill, down from $6.2 \%$ in 1988 and $4.9 \%$ in $1993 .{ }^{11}$ In the same survey it was identified that $78 \%$ of the people currently using traditional methods cited side effects of medical methods as their reason for not choosing a medical method. ${ }^{11}$ In other research carried out in Istanbul it was found that of those using no contraception, $46 \%$ rejected the pill on the basis of perceived health risks. ${ }^{13}$ This was supported by our study: both sexes expressed concerns about health risks, but men reported more negative views than women about the pill.

Research carried out in the USA reported that women had more favourable perceptions of the pill than men. ${ }^{14}$ In our study men generally knew less about contraceptives than women. This is due to three factors: women have greater experience of using contraception than men, women's health is directly affected by using contraceptives, and family planning activities in Turkey are exclusively directed towards women. Similarly, in the
United Arab Emirates the percentages of men and women who were aware of OCs were $37.9 \%$ and $85.5 \%$, respectively. ${ }^{15,16}$ Despite the immense body of evidence regarding the safety of $\mathrm{OCs}$, the perceived health risks are often exaggerated. ${ }^{17}$ The perceived side effects of the pill were of greater concern to both men and women than the side effects of other medical methods and were a major factor influencing their decision whether to use the pill and continue with it. Female participants in our study mentioned side effects of the pill such as an increase in body weight, headaches, nervousness, dizziness and irregularities in menstruation. In other research from Istanbul women described nervousness and gastric complaints as common side effects of the pill. ${ }^{18}$ In a study from India the major complaints about the pill were nausea, giddiness and headache, ${ }^{19}$ in Tasmania a slight increase in breast swelling and tenderness and weight gain ${ }^{20}$ and in China spotting. ${ }^{21}$ In a Finnish study the major concerns about OCs were cardiovascular effects, cancer, infertility, mood changes and weight gain. ${ }^{22}$ In a Russian study to identify why the pill was so unpopular, focus group participants described the pill as harmful, ineffective, untrustworthy and difficult to obtain. ${ }^{23}$ In our study participants believed that prolonged use of the pill could lead to cancer, which concurs with research on adolescents who also believed the pill to be carcinogenic. ${ }^{24}$ In a study from Nigeria the main barriers to women using medical methods were side effects $(34 \%)$, ignorance $(23 \%)$ and religion $(16 \%) .^{25}$ In our study very few participants stated religion as a factor.

It was found in our study that during family planning consultations the health care professional did not recommend OCs as the first choice of contraception but focused on health conditions that restrict the use of the pill This was one of the main reasons why women did not choose the pill as their method of contraception. This has been supported by other research, which showed that the vast majority of doctors specialising in family planning were biased against the pill and their attitude had a direct relationship on society's belief that the pill was a harmful method of contraception. ${ }^{23}$ Reasons cited by the participants for the lack of trust in medical methods were as follows: the health care professional's behaviour, bias or negative attitude, the patient's lack of knowledge and insufficient information, the price of contraceptive services, and failure in coping with problems that arose from pill use.

We also report some stated positive health effects of the pill including a reduction in dysmenorrhoea and menorrhagia and menstrual cycle regulation, which concurs with the results of a Swiss study. ${ }^{26}$

\section{Conclusions}

Public education, and in particular educating men, appears to be very important regarding the use of OCs. Moreover, family planning services should also be directed towards men or they will continue to receive only 'second-hand information' from their wives. Health care providers seem to be one of the major barriers to the use of OCs. New refresher courses addressing OCs seem to be necessary to change the attitudes of health care providers. These courses must also emphasise good counselling techniques.

\section{Acknowledgements}

The authors wish to thank Prof. Dr Ayse Akin of Hacettepe University Faculty of Medicine Department of Public Health who was a member and later the chair of the Standing Committee of the Regional Committee of the World Health Organization (WHO) and Dr Iqbal Shah of the WHO for encouraging us to submit the research proposal to the WHO. Prof. Dr Ian Diamond, Chief Executive of the Economic and Social Research Council, and Ms Sue High of the University of Southampton Faculty of Social Sciences advised on the design of the study and conducted the training 
workshop on qualitative research techniques and the Ethnograph ${ }^{\circledR}$ software, respectively. Research assistants Seyhan Hidiroglu and Sebahat Torun helped to organise the focus groups. The authors would also like to thank the participants who joined the focus groups.

Statements on funding and competing interests

Funding. This article is based on the project entitled 'Beliefs and values of men and women about contraceptive methods'. The Special Programme of Research, Development and Research Training in Human Reproduction of the WHO financially supported the project.

Competing interests. None identified.

\section{References}

1 Yusuf F, Siedlecky S. Contraceptive use in Australia: evidence from the 1995 National Health Survey. Aust N Z J Obstet Gynaecol 1999; 39: $58-62$.

2 Oddens BJ, Milsom I. Contraceptive practice and attitudes in Sweden 1994. Acta Obstet Gynecol Scand 1996; 75: 932-940.

3 Skjeldestad FE. Choice of contraceptive modality by women in Norway. Acta Obstet Gynecol Scand 1994; 73: 48-52.

4 Toulemon L, Leridon $\mathrm{H}$. Contraceptive practices and trends in France. Fam Plann Perspect 1998; 30: 114-120.

5 Oddens BJ. Contraceptive use and attitudes in Italy 1993. Hum Reprod 1996; 11: 533-539.

6 Konje JC, Oladini F, Otolorin EO, et al. Factors determining the choice of contraceptive methods at the Family Planning Clinic, University College Hospital, Ibadan, Nigeria. Br J Fam Plann 1998; 24: $107-110$

7 Oddens BJ. Determinants of contraceptive use among women of reproductive age in Great Britain and Germany. II: Psychological factors. J Biosoc Sci 1997; 29: 437-470.

8 Libbus K, Kridli S. Contraceptive decision making in a sample of Jordanian Muslim women: delineating salient beliefs. Health Care Women Int 1997; 18: 85-94.

9 Agadjanian V. Women's choice between indigenous and Western contraception in urban Mozambique. Women Health 1998; 28: 1-17.

10 Lethbridge DJ, Wang R. Patterns of contraceptive use among urban women in Taiwan. Health Care Women Int 1991; 12: 431-441.

11 Turkish Demographic and Health Survey. Hacettepe University Institute of Population Studies, Ankara, Turkey, Measure/DHS + Macro International Inc. New York, NY: United Nations Population Fund (UNFPA), 1998.
12 United Nations Population Fund (UNFPA). Contraceptive Requirements and Logistics Management Needs in Turkey. Technical Report No. 15. New York, NY: UNFPA, 1994.

13 Bulut A, Filippi V, Marshall T, et al. Contraceptive choice and reproductive morbidity in Istanbul. Stud Fam Plann 1997; 28: 35-43.

14 Grady WR, Klepinger DH, Nelson-Wally A. Contraceptive characteristics: the perceptions and priorities of men and women. Fam Plann Perspect 1999; 31: 168-175.

15 Ghazal-Aswad S, Rizk DE, Al-Khoori SM, et al. Knowledge and practice of contraception in United Arab Emirates women. J Fam Plann Reprod Health Care 2001; 27: 212-216.

16 Ghazal-Aswad S, Zaib-Un-Nisa S, Rizk DE, et al A study on the knowledge and practice of contraception among men in the United Arab Emirates. J Fam Plann Reprod Health 2002; 28: 196-200.

17 Davis A, Wysocki S. Clinician/patient interaction: communicating the benefits and risks of oral contraceptives. Contraception 1999; 59(Suppl.): $39 \mathrm{~S}-42 \mathrm{~S}$.

18 Bulut A, Yolsal N, Kayaturk F, et al. Contraceptive methods used in Istanbul and factors affecting method choice and continuation Nufusbil Derg 1996; 17-18: 3-19.

19 Kanojia JK, Nirbhavane NC, Toddywala VS, et al. Dynamics of contraceptive practice amongst urban Indian women. Natl Med J India 1996; 9: 109-112.

20 Riddoch GG, Duncombe P, Kovacs G. Tasmanian survey of pill symptoms. Aust Fam Physician 1996; 25(Suppl. 1): S38-S40.

21 Oakley D, Yu MY, Zhang YM, et al. Combining qualitative with quantitative approaches to study contraceptive pill use. J Womens Health 1999; 8: 249-257.

22 Sihvo S, Hemminki E, Kosunen E. Contraceptive health risks women's perceptions. J Psychosom Obstet Gynaecol 1998; 19: $117-125$

23 Popov AA, Visser AP, Ketting E. Contraceptive knowledge, attitudes, and practice in Russia during the 1980s. Stud Fam Plann 1993; 24: 227-235.

24 Berglund S, Liljestrand J, Marin FM, et al. The background of adolescent pregnancies in Nicaragua: a qualitative approach. Soc Sci Med 1997; 44: 1-12.

25 Renne EP. Local and institutional interpretations of IUDS in Southwestern Nigeria. Soc Sci Med 1997; 44: 1141-1148.

26 Oddens BJ. Women's satisfaction with birth control: a population survey of physical and psychological effects of oral contraceptives, intrauterine devices, condoms, natural family planning and sterilization among 1466 women. Contraception 1999; 59: 277-286.

\section{But is she positive?}

Your next patient is pregnant but doesn't want to be.

Where next? As a registered charity since 1968, bpas has offered affordable abortion care for women. We provide almost 50,000 abortions a year (including service agreements) and can offer all the professional help your patient needs.

bpas has a nationwide network of clinics and consultation centres. There are no long waits for appointments. We can offer a choice of times, clinics and procedures. All it takes to arrange an appointment is one call to the bpas Actionline on 08457304030.

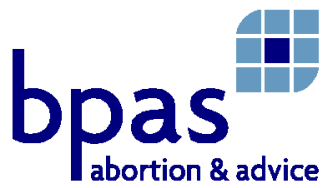

ACTIONLINE 08457304030

\section{bpas positively the best service}

